\title{
PROBLEMAS ADMINISTRATIVOS Y PRESUPUESTALES DE LA EDUCACION PRIMARIA OFICIAL*
}

\author{
Por Rodrigo Losada Lora y \\ Hernando Gómez Buendía**
}

La investigación, realizada por FEDESARROLLO, analiza las raíces financieras, administrativas, laborales y políticas de los conflictos huelguísticos protagonizados por los maestros oficiales de primaria durante los años 1968-19 79. Las fuentes de datos son diversas: el escrutinio de las principales huelgas del magisterio en el período referido; el estudio pormenorizado de la administración educativa en dos departamentos, Antioquia y Magdalena, y su relación con las huelgas docentes acaecidas en ellos, diversos análisis de cifras presupuéstales de la nación, de datos salariales y de documentos legales pertinentes; y una amplia serie de entrevistas con personas particularmente entendidas en ciertos aspectos específicos del tema de la investigación.

Antes de tratar los problemas de tipo financiero, presupuestal y administrativo de la educación oficial, especialmente la de nivel básico, detectados por las dos investigaciones mencionadas, conviene recordar algunas grandes tendencias del gasto público en el sector educativo.

\section{Algunas tendencias del gasto público en el sector educativo}

Como primer punto de referencia, el Cuadro No. 1 describe la importancia relativa del gasto público total en educación dentro del producto interno bruto y dentro del Presupuesto Nacional. Se nota allí que los países industrializados destinan a educación un mayor porcentaje de su producto interno que las naciones en vía de desarrollo y que la cuota de estas últimas aumentó entre los dos años de referencia. De su lado, el esfuerzo público colombiano es menor que el promedio del de los países en desarrollo (pese a que el producto per cápita de Colombia es superior a tal promedio) y disminuyó entre los dos años comparados. Pero la anterior imagen cambia por entero al examinar los porcentajes sobre Presupuesto Nacional. La diferencia entre desarrollados y en desarrollo se acorta visiblemente. Colombia se aproxima y hasta excede el promedio para los no industrializados, y su porcentaje aumenta más rápidamente que aquel promedio.

\footnotetext{
* Ponencia presentada en el seminario sobre "Aspectos relevantes de la Educación Primaria Rural, organizado por el CIII) en septiembre de 1981 en Bogotá.

${ }^{* *} \mathrm{Ph}$. D. Ciencia Política, U. de Georgetown, USA. Investigador Fedesarrollo; Profesor investigador, Universidad Javeriana.

** Abogado, M.A. Economía, Ph. D. Sociología. Director Alterno de Fedesarrollo, Profesor Asociado de la Universidad de Pittsburgh. 
CUADRO No. 1

\section{GASTO PÚBLICO TOTAL EN EDUCACION COMO PORCENTAJE DEL PRODUCTO INTERNO BRUTO Y DEL PRESUPUESTO NACIONAL $1970-1974$}

\begin{tabular}{|l|l|l|l|l|}
\hline & \multicolumn{2}{|c|}{ PIB } & \multicolumn{2}{c|}{$\begin{array}{l}\text { Presupuesto } \\
\text { nacional }\end{array}$} \\
\hline & $\mathbf{1 9 7 0}$ & $\mathbf{1 9 7 4}$ & $\mathbf{1 9 7 0}$ & $\mathbf{1 9 7 4}$ \\
\hline $\begin{array}{l}\text { Países } \\
\text { desarrollados }\end{array}$ & 5.7 & 5.7 & 16.1 & 15.6 \\
\hline $\begin{array}{l}\text { Países en } \\
\text { desarrollo }\end{array}$ & 3.4 & 3.9 & 13.8 & 15.1 \\
\hline Colombia & 3.2 & 2.8 & 13.6 & 18.4 \\
\hline
\end{tabular}

Fuente: World Bank, Education - Sector Policy Paper, 1980, p. 67, para Colombia, cálculos de FEDESARROLLO.

Ahora bien: interpretadas en su conjunto, las cifras del Cuadro 1 apuntan a conclusiones más elaboradas. Primero: entre más desarrollado es un país, mayor es la participación de gasto público educativo en el producto interno bruto y en el Presupuesto Nacional. Segundo, el Presupuesto Nacional representa un porcentaje menor del producto total en los países subdesarrollados que en los industrializados (por ello el bache relativo entre los primeros y los segundos se acorta según se elija una u otra base de comparación). Tercero, el sector público colombiano participa menos del producto total que el promedio de los países en desarrollo. Cuarto, pese a ser un "estado débil", el esfuerzo educativo del gobierno colombiano es notable en comparación de países con similar y superior nivel de desarrollo. Quinto, parte del aumento registrado entre 1970 y 1974 debe atribuírse a cambios en el esquema de financiación colombiano, como se verá más adelante.

Otras comparaciones internacionales de interés se desprenden del Cuadro No. 2. El gasto público por estudiante se eleva a medida que los países alcanzan mayores índices en su ingreso per cápita, y el salto es espectacular al pasarse la barrera de los US\$2.500 por habitante. Pero, si se descuenta el rezago de los muy pobres (menos de US\$265) la tasa de crecimiento del gasto público educativo fue mayor entre los subdesarrollados que entre los miembros de la OECD, entre 1970 y 1975 . Si se recuerda que el ingreso per cápita de Colombia era de US\$ 630, parecería que el gasto público por estudiante del país está dentro del rango esperado para su grado de desarrollo. Pero habría que tener en cuenta otras circunstancias, infortunadamente no cuantificables: la menor participación del ingreso público sobre el producto nacional, la incidencia relativa de la matrícula privada, y la distintas composición y costos del alumno por tramos educativos. En cambio, es claro que el gasto público por estudiante creció un poco más rápidamente durante el quinquenio en Colombia que en el promedio de los países con grado comparable de desarrollo económico.

Tocante a los costos per cápita en primaria, vuelve a anotarse su incremento al elevarse el ingreso por habitante y la abrupta discontinuidad al superar el límite de los US\$ 2.500 anuales. Si se escrutan las diferencias relativas entre Colombia y los países que se encuentran en su mismo tramo de ingreso, podría flotar la impresión que los 
costos por estudiante colombiano son bastante elevadas. Pero ello quizás no pasa de ser una impresión en vista de las salvedades anotadas y, más aún, en ausencia de indicadores sobre la calidad de la educación impartida.

Mirando ahora algunas cifras colombianas, el Cuadro No. 3 presenta la evolución del gasto público educativo, incluyendo la Nación y los Departamentos, entre 1968 y 1980. En doce años, los recursos públicos destinados al sector prácticamente se han duplicado en pesos constantes, lo cual implica una tasa de crecimiento anual superior al $6 \%$. Pero este guarismo resulta menos impresionante cuando se recuerda que es cercano a la tasa de expansión real de los ingresos del sector público, o cuando se le compara con la de crecimiento del producto bruto durante el mismo período. En cambio, la contribución gubernamental a la educación ha aumentado con bastante más rapidez que el ingreso per cápita.

CUADRO No. 2

GASTO PÚBLICO EN EDUCACION POR ESTUDIANTE (1970 y 1975) Y COSTOS POR ESTUDIANTE

DE PRIMARIA (1975)

En dólares corrientes

\begin{tabular}{|l|c|c|c|}
\hline $\begin{array}{c}\text { Países con PIB } \\
\text { Per cápita de 1975 }\end{array}$ & \multicolumn{2}{|c|}{ Gasto total } & $\begin{array}{c}\text { Costos en } \\
\text { primaria 1970 }\end{array}$ \\
\hline Menos de \$265 & 39 & 40 & 26 \\
\hline Entre \%265 y \$520 & 43 & 109 & 57 \\
\hline Entre \%521 y \$1.075 & 73 & 177 & 88 \\
\hline Colombia $\mathbf{\$ 6 3 0 )}$ & 68 & 169 & 86 \\
\hline Entre \$1.076 y \$2.500 & 140 & 305 & 182 \\
\hline Miembros de la OECD & 848 & 1.238 & 859 \\
\hline
\end{tabular}

* Europa Occidental, Turquía, Estados Unidos, Canadá, Japón, Australia y Nueva Zelandia.

Fuente: World Bank, Education - Sector Policy Paper, 1980, p. 71; para Colombia, cálculos de FEDESARROLLO. 
CUADRO No. 3

GASTO PÚBLICO TOTAL EN EDUCACION

$1968-1979$

\begin{tabular}{|l|l|l|l|r|}
\hline Año & $\begin{array}{c}\text { Pesos } \\
\text { corrientes } \\
\text { (Millones) }\end{array}$ & $\begin{array}{c}\text { Índice de } \\
\text { crecimiento }\end{array}$ & $\begin{array}{c}\text { Pesos } \\
\text { constantes } \\
\text { (millones) }\end{array}$ & $\begin{array}{c}\text { Índice de } \\
\text { crecimiento }\end{array}$ \\
\hline $\mathbf{1 9 6 8}$ & 2528.3 & 100.0 & 3113.7 & 100.0 \\
\hline $\mathbf{1 9 6 9}$ & 3195.9 & 126.3 & 3566.8 & 114.5 \\
\hline $\mathbf{1 9 7 0}$ & 4182.6 & 165.3 & 4182.6 & 134.3 \\
\hline $\mathbf{1 9 7 1}$ & 5187.8 & 205.1 & 4562.7 & 146.5 \\
\hline $\mathbf{1 9 7 2}$ & 6238.7 & 246.6 & 4824.9 & 154.9 \\
\hline $\mathbf{1 9 7 3}$ & 7582.1 & 299.7 & 4879.1 & 156.6 \\
\hline $\mathbf{1 9 7 4}$ & 9320.4 & 368.5 & 4824.2 & 154.9 \\
\hline $\mathbf{1 9 7 5}$ & 11800.4 & 466.5 & 4933.3 & 158.4 \\
\hline $\mathbf{1 9 7 6}$ & 13921.1 & 550.4 & 4872.6 & 156.4 \\
\hline $\mathbf{1 9 7 7}$ & 17944.5 & 709.5 & 5211.9 & 167.4 \\
\hline $\mathbf{1 9 7 8}$ & 24825.0 & 981.5 & 5929.1 & 190.4 \\
\hline $\mathbf{1 9 7 9}$ & 33628.3 & 1330.1 & 6170.5 & 198.2 \\
\hline
\end{tabular}

Fuente: Cuadro No. 4.

Si el gasto público en educación ha crecido al compás de los ingresos totales del estado, se ha producido en cambio una variación sustancial en los esfuerzos relativos de la Nación y de los departamentos. El Cuadro No. 4 muestra cómo, en efecto, los aportes reales de Presupuesto Nacional aumentaron en un 186\% entre 1968 y 1978, al paso que los recursos departamentales disminuyeron en valor real en un $24 \%$. Más aún, en tanto que la cuota de los presupuestos departamentales destinada a la educación parece disminuir ligeramente (descendió de $39.6 \%$ en 1971 a $36.1 \%$ en $1974^{67}$ ), el Cuadro No. 5 testifica la creciente importancia relativa de la educación dentro del presupuesto del nivel central, como que su porcentaje pasó de 12.5 a 20.0 en $1978^{68}$. La consecuencia de tales tendencias en contraste se refleja en que la Nación haya pasado de sufragar el $54.4 \%$ del esfuerzo público total para la educación en 1968 al $85 \%$ en 1979, mientras los Departamentos y demás territorios bajaron de aportar el 45.4 al 15.2\% (Ver Cuadro No. $6)$.

\footnotetext{
${ }^{67}$ Según ejecuciones contabilizadas por la Contraloría General de la República y cálculos de FEDESARROLLO. No fue posible ampliar la serie histórica sobre bases comparables.

${ }^{68} \mathrm{La}$ disminución de 1981 puede atribuirse a la circunstancia de que las cifras no incluyen todas las adiciones.
} 
CUADRO No. 4

GASTO NACIONAL Y DEPARTAMENTAL EN EDUCACIÓN, 1968 - 1980

(Millones de pesos)

\begin{tabular}{|c|c|c|c|c|c|c|c|c|}
\hline & \multicolumn{4}{|c|}{ Presupuesto nacional } & \multicolumn{4}{|c|}{ Presupuesto departamental } \\
\hline Año & $\begin{array}{c}\text { Pesos } \\
\text { corrientes }\end{array}$ & $\begin{array}{c}\text { Índice de } \\
\text { crecimiento }\end{array}$ & $\begin{array}{c}\text { Pesos } \\
\text { constantes }^{1}\end{array}$ & $\begin{array}{c}\text { Índice de } \\
\text { crecimiento }\end{array}$ & $\begin{array}{c}\text { Pesos } \\
\text { corrientes }\end{array}$ & $\begin{array}{c}\text { Índice de } \\
\text { crecimiento }\end{array}$ & $\begin{array}{c}\text { Pesos } \\
\text { corrientes }\end{array}$ & $\begin{array}{l}\text { Índice de } \\
\text { crecimiento }\end{array}$ \\
\hline 1968 & 1379.3 & 100.0 & 1698.6 & 100.0 & 1149.0 & 100.0 & 1415.0 & 100.0 \\
\hline 1969 & 1865.9 & 135.3 & 2082.5 & 122.6 & $1330.0^{2}$ & 115.7 & 1484.4 & 104.9 \\
\hline 1970 & 2487.6 & 180.3 & 2487.6 & 146.4 & 1695.0 & 147.5 & 1695.0 & 119.7 \\
\hline 1971 & 3302.8 & 239.4 & 2904.8 & 171.0 & 1885.0 & 164.0 & 1657.9 & 117.1 \\
\hline 1972 & 4118.7 & 298.6 & 3185.4 & 187.5 & 2120.0 & 184.5 & 1639.6 & 115.8 \\
\hline 1973 & 5549.1 & 402.3 & 3570.8 & 210.2 & 2033.0 & 176.9 & 1308.2 & 92.4 \\
\hline 1974 & 6646.4 & 481.8 & 3440.1 & 202.5 & 2674.0 & 232.7 & 1370.1 & 96.8 \\
\hline 1975 & 8561.4 & 620.7 & 3579.2 & 210.7 & 3239.0 & 281.8 & 1354.1 & 95.6 \\
\hline 1976 & 10439.7 & 756.9 & 3654.1 & 215.1 & $3481.4^{*}$ & 303.0 & 1218.5 & 86.1 \\
\hline 1977 & 14275.9 & 1035.0 & 4146.3 & 244.1 & $3668.6^{*}$ & 319.3 & 1065.5 & 75.3 \\
\hline 1978 & 20326.5 & 1473.6 & 4854.6 & 285.8 & $4498.5^{3 *}$ & 391.5 & 1074.4 & 76.0 \\
\hline 1979 & 28562.0 & 2070.8 & & & $5066.3^{*}$ & 440.9 & & \\
\hline 1980 & 37924.0 & 2749.5 & & & & & & \\
\hline
\end{tabular}

${ }^{1}$ Se empleó como deflactor el de precios implícitos para gastos de consumo del gobierno.

${ }^{2}$ Interpolación

${ }^{3}$ No incluye Valle del Cauca, Quindío ni Chocó, por falta de información

* Presupuesto; las demás cifras corresponden a ejecuciones.

Fuentes: Presupuesto Nacional 1968-2978; Contraloría General de la República, Informes Financieros; 1979, id. (Avance); 1980, Ley de Presupuesto. Presupuesto Departamental; 1968 - 1975, J. Ospina, Recopilación de Estadística de Ingresos y Gastos de los diferentes niveles de I sector público, FEDESARROLLO, Bogotá, 1976 (mimeo) cuadro 24a; 1976-1979, dirección general de presupuesto, proyectos de presupuesto. 


\section{CUADRO No. 5}

\section{PRESUPUESTO TOTAL DE LA NACION Y PRESUPUESTO DE EDUCACION 1968- 1980 \\ (Miles de pesos)}

\begin{tabular}{|c|l|c|r|}
\hline Años & $\begin{array}{c}\text { Presupuesto total } \\
\text { de la Nación } \\
\mathbf{( 1 )}\end{array}$ & $\begin{array}{c}\text { Presupuesto } \\
\text { total de } \\
\text { educación del } \\
\text { sector central } \\
\mathbf{( 2 )}\end{array}$ & $\begin{array}{c}\text { Participación } \\
\mathbf{( 3 )} \\
\mathbf{( 2 / 1 ) \times 1 0 0}\end{array}$ \\
\hline $\mathbf{1 9 6 8}$ & 11.011 .300 & 1.379 .283 & 12.5 \\
\hline $\mathbf{1 9 6 9}$ & 14.664 .000 & 1.865 .955 & 12.7 \\
\hline $\mathbf{1 9 7 0}$ & 18.237 .600 & 2.487 .568 & 13.6 \\
\hline $\mathbf{1 9 7 1}$ & 22.291 .400 & 3.302 .827 & 14.8 \\
\hline $\mathbf{1 9 7 2}$ & 24.064 .251 & 4.118 .672 & 17.1 \\
\hline $\mathbf{1 9 7 3}$ & 29.802 .200 & 5.549 .120 & 18.6 \\
\hline $\mathbf{1 9 7 4}$ & 36.018 .200 & 6.646 .410 & 18.4 \\
\hline $\mathbf{1 9 7 5}$ & 49.846 .100 & 8.561 .468 & 17.1 \\
\hline $\mathbf{1 9 7 6}$ & 52.795 .700 & 10.439 .680 & 19.7 \\
\hline $\mathbf{1 9 7 7}$ & 72.784 .137 & 14.275 .901 & 19.6 \\
\hline $\mathbf{1 9 7 8}$ & 101.143 .100 & 20.326 .592 & 20.0 \\
\hline $\mathbf{1 9 7 9}$ & 151.511 .000 & 28.562 .000 & 18.8 \\
\hline $\mathbf{1 9 8 0}$ & 195.117 .000 & 37.924 .000 & 19.4 \\
\hline $\mathbf{1 9 8 1}$ & 201.638 .582 & 38.063 .881 & 18.9 \\
\hline
\end{tabular}

Fuente: 1968-1980 - Contraloría General de la República, Informes Financieros 1981. Ley de Presupuesto.

A continuación se entra a discutir algunos problemas principales de tipo administrativo y financiero detectados por los estudios aquí considerados. Para apreciarlos mejor en su contexto conviene aludir primero a la evolución de las responsabilidades financiera y administrativas entre los varios niveles del Gobierno, las cuales conciernen a la educación primaria. Y tratar, luego, otros desarreglos administrativos y presupuéstales detectados durante dichas investigaciones. Estas secciones concluyen con una serie de sugerencias de política oficial.

\section{Las responsabilidades administrativas y financieras y su evolución}

En la medida en que los estudios aquí reseñados buscan las causas principales, sea de las huelgas docentes, sea de la insuficiencia y/o ineficacia del gasto público en la escuela rural, se hicieron patentes dos problemas de fondo. Primera, no es claro a cuál nivel del gobierno le compete hoy prestar el servicio de la educación primaria. Segundo, en los últimos dos decenios ha tenido lugar un agudo divorcio entre recursos y competencias en materia de enseñanza primaria oficial. O dicho esto último en otras palabras, se ha perdido la unidad administrativa de mando, necesaria no sólo para el suministro eficiente y efectivo de este servicio, sino de cualquier otro servicio. Conviene documentar estos dos puntos. 
CUADRO No. 6

PARTICIPACION PORCENTUAL DE

LOS PRESUPUESTOS NACIONAL Y

DEPARTAMENTAL EN LOS GASTOS

EN EDUCACION

\begin{tabular}{|l|c|c|}
\hline Año & $\begin{array}{c}\text { Recursos } \\
\text { Departamentales } \\
\text { para educación/ } \\
\text { Total educación }\end{array}$ & $\begin{array}{c}\text { Recursos } \\
\text { Nacionales } \\
\text { Para } \\
\text { educación/ } \\
\text { Total } \\
\text { educación }\end{array}$ \\
\hline 1968 & 45.4 & 54.5 \\
\hline 1969 & 41.6 & 58.3 \\
\hline 1970 & 40.5 & 59.4 \\
\hline 1971 & 36.3 & 63.6 \\
\hline 1972 & 33.9 & 66.0 \\
\hline 1973 & 26.8 & 73.0 \\
\hline 1974 & 28.6 & 71.3 \\
\hline 1975 & 27.4 & 72.5 \\
\hline 1976 & 25.0 & 75.0 \\
\hline 1977 & 20.4 & 79.5 \\
\hline 1978 & 18.1 & 81,8 \\
\hline 1979 & 15.2 & 85.0 \\
\hline
\end{tabular}

Nota: Los porcentajes no suman 100 debido a cálculo independiente.

Fuente: Cuadros 3 y 4 .

A. El problema de la competencia, o a quién compete primariamente suministrar la enseñanza primaria?

Desde la misma Constitución de 1886, la distribución de responsabilidades concernientes a la educación primaria ha sufrido de ambigüedades, y las continúa adoleciendo. Pues los autores de la Carta de 1886 pusieron en manos del Presidente de la República la tarea de "Reglamentar, dirigir e inspeccionar la instrucción pública nacional", sea ésta ofrecida por el Estado, sea por particulares ${ }^{69}$. Se trata, pues, de una competencia que confía al Jefe del Estado suprema autoridad administrativa, la dirección y ejecución de la política educativa del país.

Pero al mismo tiempo, la Carta entregó a los Departamentos, y no a la Nación, la obligación de "dirigir y fomentar" la enseñanza elemental ${ }^{70}$. Se podrían conciliar las dos normas, y así se buscó hacerlo, tomando la primera como una expresión del principio de la "centralización política" y refiriéndola a la política educativa "general" del país, y considerando la segunda como una instancia de la "descentralización administrativa", propugnada por el Constituyente del 86. Sin embargo, puesto que en uno y otro texto se habla de "dirigir", la ambigüedad subsistió. Más aún, fue reforzada por la ley 39 de 1903,

\footnotetext{
${ }^{69}$ Art. 120, ordinal 15, de la Constitución Nacional de 1886.

${ }^{70}$ El texto original reza: "Corresponde a las Asambleas dirigir y fomentar, por medio de ordenanzas y con los recursos propios del Departamento, la instrucción primaria...” (Art. 185 de la mencionada Constitución de 1886.
} 
ley marco que ha regido la educación del país durante la mayor parte del presente siglo, la cual estatuyó que: La "instrucción pública, costeada con fondos públicos,.., estará a cargo y bajo la inmediata dirección y protección de los Gobiernos de los Departamentos" ${ }^{\prime 1}$.

No extraña entonces que en 1910 se haya modificado la Carta precisamente en el respecto aludido. Se suprimió uno de los dos verbos "dirigir" que figuraban en la Carta del 86 -el que atañe a los departamentos. El nuevo texto, vigente hasta 1968, quedó entonces así: "Corresponde a las Asambleas... Reglamentar por medio de ordenanzas y de acuerdo con los preceptos constitucionales los establecimientos de instrucción primaria,.. Cuando fueren costeados con fondos del Departamento"72. Así se solucionó un problema de competencias pero se dio origen a otro. Se resolvió el conflicto jerárquico entre la Nación y los Departamentos: aquella "dirige", estos "reglamentan". Pero al usar el giro "cuando fueren costeados con fondos del Departamento" se reconoció la posibilidad de que otros niveles de gobierno, el nacional y el municipal, pudiesen atender también a la educación primaria. Con lo cual se creó un vacío normativo, porque desde entonces no se sabe a quién compete en propiedad la prestación de dicho servicio. Si se la sigue atribuyendo ante todo a los Departamentos es simple consecuencia de la primacía de hecho ejercida por estos en el suministro de tal servicio, primacía manifiesta hasta mediados del presente siglo pero cuestionable en las últimas dos décadas.

Como reflejo de la progresiva debilidad financiera de los Departamentos, de su frecuente incapacidad administrativa, y de la conveniencia de una mayor centralización en el suministro de ciertos servicios, la Reforma Constitucional de 1968 optó por abrir la puerta a una nueva y mas funcional redistribución de obligaciones entre la Nación y los entes territoriales en materia de servicios públicos ${ }^{73}$. En concreto, se ordenó entonces que "Salvo lo dispuesto por la Constitución, la ley a iniciativa del Gobierno, determinará los servicios a cargo de la Nación y de las entidades territoriales, teniendo en cuenta la naturaleza, importancia y costos de los mismos"74.

Aun cuando ha quedado así despejada la vía para una clara definición de competencias, tal posibilidad no ha sido aprovechada por el gobierno nacional. En cambio se ha dejado subsistir un estado de cosas que, en lo que atañe a los servicios educativos de primaria, se comporta como si a los Departamentos y a los demás entes territoriales del mismo orden correspondiese la prestación de dichos servicios, por supuesto auxiliados financiera-mente por la Nación.

La ambigüedad actual se hace patente cuando se contrastan los textos legales relativos al situado fiscal con los de la nacionalización educativa ordenada en 1975. Porque el sistuado fue concebido como una transferencia obligatoria de recursos nacionales a fin de atender en forma eficaz los servicios propios de los Departamentos, las Intendencias y

\footnotetext{
${ }^{71}$ Ley 39 de 1903, art. 3. El subsiguiente artículo de dicha ley determina que "La instrucción secundaria será de cargo de la Nación... Esto no obsta para que los Departamentos y Municipios que dispongan de recursos suficientes sostengan establecimientos de enseñanza secundaria".

${ }^{72}$ Art. 54 del Acto Legislativo No. 3 de 1910. Este texto sufrió una ligera modificación en 1945 (Art. 83 del Acto Legislativo No. 1 de dicho año).

${ }^{73}$ Ver los diversos comentarios al respecto por los ponentes de los proyectos de reforma, en Presidencia de la República, Historia de la reforma constitucional de 1968 (Bogotá: Imprenta Nacional, 1969), pp. 382, 432 y passim.

${ }^{74}$ Art. 53 del Acto Legislativo No. 1 de 1968. Art. 182 de la Constitución Nacional vigente. Quizá como consecuencia de este principio general, las funciones "reglamentarias" de las Asambleas en materia de instrucción primaria ya relatadas, fueron omitidas en la reforma de 1968, y en su lugar apareció la siguiente fórmula general: "Corresponde a las Asambleas.., reglamentar de acuerdo con los preceptos constitucionales y legales, la prestación de los servicios a cargo del Departamento" (Art. 57 del Acto Legislativo No. 1 de 1968; art. 187 de la Constitución Nacional vigente).
} 
Comisarías, y el Distrito Especial de Bogotá $^{75}$. Ahora bien, al expresar la ley 46 de 1971 que el "situado fiscal" está destinado exclusivamente "para gastos de funcionamiento de educación primaria y salud pública" (Art. 1), está implícitamente afirmando que estos dos servicios son propios de los entes territoriales referidos.

Por otro lado, tres años después, la Ley 43 de 1975 declara de manera rotunda: "La educación primaria y secundaria oficial será un servicio público a cargo de la Nación" (Art. 1). Se transfirieron entonces las competencias de los Departamentos a la Nación? No. Tras el lenguaje taxativo de la Ley 43 sólo existe una realidad financiera. El "a cargo" significa que "los gastos que ocasionen (la educación primaria y secundaria) y que hoy sufragan los Departamentos, Intendencias, Comisarias, el Distrito Especial de Bogotá y los Municipios, serán de cuenta de la Nación, en los términos de la presente Ley" (Art. 1). Dado que, en lo tocante a la enseñanza primaria, la casi totalidad de sus costos estaba ya siendo atendida con el situado fiscal, lo que la Ley 43 propiamente "Nacionaliza" es poco. Al parecer, no se extiende más allá del costo de las prestaciones sociales causadas a partir de 1976. Por tanto, la Ley 43 deja en pie la atribución del servicio educativo de primaria a los Departamentos y demás entes territoriales del mismo orden, que la ley del situado y otras disposiciones legales implican, pero que ninguna de ellas con claridad establece $^{76}$.

La identificación de competencias en materia de educación primaria conduce a situaciones caóticas desde el punto de vista administrativo y financiero. Aunque la Nación tomó a su cargo el pago de dicha educación, no se quitó a los Departamentos o Municipios la facultad para crear y mantener a su costa plazas docentes. De ahí que hoy en día un Gobernador pueda nombrar, dentro de ciertos límites presupuéstales, cien o quinientos maestros, o cualquier número, con tal que lo haga con cargo a los recursos del Departamento. Pero qué pasa? Que un gobernador irresponsable puede nombrar $X$ número de maestros, aún conociendo a cabalidad que los recursos departamentales son insuficientes para ese fin. Como declarar la insubsistencia masiva de cien o quinientos maestros, es una medida muy impopular y políticamente muy difícil de defender, una vez creado el hecho es casi imposible deshacerlo. Qué sucede entonces? Que el Gobernador irresponsable se retira de su cargo, sin posibilidad alguna de imponerle una sanción por su irresponsabilidad, y su sucesor acude al Ministerio para que le ayude a solucionar el problema. El desenlace justamente llega cuando el FER de la región termina por incorporar a su nómina, por orden o insinuación del Ministerio, los docentes nombrados con cargo al fisco departamental. En el estado de cosas actual, no hay manera de impedir la repetición de tales abusos.

El segundo ejemplo atañe las primas extralegales del magisterio. Porque en virtud de la aludida indefinición de competencias, las autoridades departamentales, la Asamblea o el Gobernador, pueden ordenar primas extralegales u otros beneficios económicos a favor de sus maestros. De hecho en casi todos los Departamentos se los ha acordado con mayor o menor generosidad. Alguien diría: Qué hay de malo en que así se estimule y premie a los docentes? Si sólo se trata de estimular y premiar, no habría problemas. Este nace cuando se quiere corregir las desigualdades regionales y hacer la docencia igualmente atractiva en un Departamento que en otro. Para lo cual se impone unificar los

\footnotetext{
${ }^{75}$ El Acto legislativo No. 1 de 1968 - Art. 182 de la Constitución Nacional vigente-, al ordenar que un porcentaje de los ingresos de la Nación sea transferido a los Departamentos, Intendencias, Comisarías y el Distrito Especial de Bogotá, dice que ello se hará "para la prestación de sus servicios y los de sus respectivos municipios" (el subrayado es nuestro). Aun cuando el texto no implica exclusividad en el suministro del servicio, sí denota por lo menos cierta prioridad en la prestación del mismo.

${ }^{76}$ Otro indicio de la ambigüedad existente en la definición de competencias sobre la enseñanza primaria yace en las funciones, hoy atribuidas a la Junta Administrativa de los FER, tal como más adelante se ilustra.
} 
sueldos. Tal unificación, pretendida por el Ministerio de Educación en los últimos años, resulta imposible si las autoridades de cada región pueden aprobar una retribución extra a sus respectivos docentes. Por otro lado, una tal facultad en poder de las autoridades regionales permite - con intención o sin ella - contrariar o entrabar de forma sustancial el desarrollo de cualquier política educativa tomada por la Nación o por el FER. Para ello basta que la Asamblea o el Gobernador acuerde unos estímulos salariales extralegales u otros incentivos contrarios a la política educativa en cuestión ${ }^{77}$.

Así, pues, la indefinición existente de competencias puede llevar, y de hecho repetidas veces está llevando, a confusas situaciones administrativas y a la ineficiencia en el uso de los escasos recursos.

B. El divorcio entre competencias y recursos. Durante la mayor parte del presente siglo, contado desde al menos 1903, existió en el campo de la enseñanza primaria oficial un arreglo administrativo que es funcional. El Departamento, y en algunas raras circunstancias, el Municipio, se imponía a sí mismo la obligación de atender X número de escuelas y lo hacía con sus propios recursos. El arreglo era eficiente porque respetaba un principio organizativo elemental, a saber, el de la unidad de la competencia con los recursos. O sea, que quien fije las metas operativas de la organización es el mismo que controla los recursos para lograrlas. En concreto, un Gobernador podía entonces, una vez calculados los ingresos del Departamento, decidir cuántas escuelas iba a poner en servicio y con cuántos maestros, podía fijar — de acuerdo con la Asamblea- el monto de los salarios y nombrar y trasladar las personas que juzgase más apropiadas para los cargos docentes. Existía pues una clara unidad de mando, en cuanto a la programación del servicio, la elaboración de su presupuesto, el manejo del personal requerido para atenderlo y su supervisión, se encontraban finalmente en una sola mano.

Si este esquema falló no es porque careciera de una bondad administrativa intrínseca, sino en virtud de otros factores. El debilitamiento progresivo de los ingresos departamentales y la irresponsabilidad administrativa de varios departamentos condujeron al divorcio entre recursos y competencias hoy conocido. El primer paso importante en esta dirección se dio en 1960 cuando la Ley 111 impuso a la Nación "el pago de los sueldos del magisterio oficial de la enseñanza primaria en todo el territorio de la República" (art. 1). Aun cuando la norma así estatuída no fue ejecutada fielmente por el Gobierno Nacional, y años después fue complementada y/o sustituida por otras disposiciones, ella entronizaba un funesto principio administrativo ${ }^{78}$, pues el que tenía la responsabilidad de otorgar el servicio, generalmente el Departamento, ya no sentía la obligación de conseguir el dinero para cubrirlo, y quien lo pagaba, la Nación, carecía de control efectivo sobre la forma como se administraba el servicio.

A fin de evitar el desvío de los fondos nacionales destinados para el pago de los maestros a otros fines - desvío conocido en ocasiones con características espectaculares durante la década del sesenta- se ideó y puso en práctica desde 1968 el mecanismo de los Fondos Educativos Regionales $(\mathrm{FER})^{79}$. En la tarea de impedir tales desvíos, los FER han constituido un éxito incuestionable. Pero han surgido otros fenómenos que han agravado el divorcio entre competencias y recursos. Por un lado, se ha registrado una creciente centralización administrativa -unida en ocasiones a una cierta

\footnotetext{
${ }^{77}$ Las aludidas facultades de las autoridades territoriales hace, además, muy difícil calcular y administrar las prestaciones sociales en el mediano y largo plazo.

${ }^{78}$ El Decreto reglamentario de la Ley 111 limitó el compromiso de la Nación al costo, en pesos corrientes, de la norma docente registrada a comienzos de 1970. Tal reglamentación equivalió en el fondo, como consecuencia del continuo proceso inflacionario experimentado por el país, a poco menos que anular en la práctica la nacionalización ordenada por la Ley.

${ }^{79}$ Decreto 3157 de 1968 , arts. 29-36. 
desconcentración de funciones- en el manejo de la enseñanza primaria oficial, en especial de su función docente. Quizás ello era inevitable a la luz del principio que reza "quien controla el dinero, controla el poder". Así, el presupuesto educativo en último término se hace ahora en Bogotá, y allí se toman también las decisiones sobre el número autorizado de plazas docentes - con cargo al fisco nacional- y sobre el monto de la remuneración del magisterio. Entre las pocas facultades que hoy conserva el Gobernador en materia de administración de los docentes de primaria, figuran: la de nombrar o destituir maestros, pero sujeta —en el caso de los maestros escalafonados y/o pagados por la Nación, que son la gran mayoría- a una serie de condiciones impuestas por ley o por el Ministerio de Educación. Segunda, la de ordenar el sitio de trabajo de los maestros. Y tercera, la de nombrar los supervisores departamentales de educación.

Frente a estas lánguidas funciones del Gobernador se encuentran las robustas de las Juntas Administradoras de los FER. Porque desde 1976 se asignaron a dichas Juntas unas tareas que habían sido las tradicionales y principales de las Secretarías de Educación Departamentales. En particular se les encargó "definir, organizar y administrar los servicios educativos de los niveles primario, secundario, medio e intermedio, de conformidad con las normas vigentes sobre instrucción pública nacional" 80 . Dado que las Secretarías de Educación no han desaparecido ni se les han modificado sus funciones, la duplicidad de estas es flagrante.

Como consecuencia, en aquellos Departamentos, casi todos, donde la Junta Administradora ha tomado a pecho el encargo citado, la Secretaría Departamental de Educación ha visto reducidos de manera notable sus quehaceres. Sólo en Departamentos como Antioquia, donde las autoridades regionales han sabido limitar la acción de la Junta Administradora del FER, continúan las Secretarías de Educación desempeñando sus atribuciones tradicionales. Pero se trata de un estado de cosas administrativamente impreciso, producto de inciertos compromisos políticos. Adviértase, además, que las Juntas Administradoras de los FER son unos entes mixtos que, para completar la ambigüedad existente, carecen de personería jurídica y no pertenecen a ningún nivel de gobierno: ni al Nacional, ni al Departamental, y obviamente no al Municipal.

De todas maneras, en el caso de la mayoría de los Departamentos, donde las Juntas Administradoras de los FER han asumido efectivamente el liderazgo en la administración educativa de primaria, el divorcio de recursos y competencias continúa imperando. Porque dichas Juntas pueden, por ejemplo, proponer la creación de plazas docentes y la creación de escuelas, pero la decisión en esta materia es tomada por el Ministerio - o el ICCE en el último caso-. Si el gobernador, quien por cierto es miembro de dicha Junta, no colabora, la Junta está inhabilitada para controlar el proceso de nombramiento de los maestros, sus traslados y la provisión de cargos administrativos en las escuelas. La Junta no disfruta sino de una muy limitada libertad en el manejo del presupuesto para la educación primaria. Las decisiones de calado en esta materia las toma, como se acaba de indicar, el Ministerio o el Departamento. Valga citar dos casos: la Junta no puede determinar estímulos salariales de ninguna índole para sus maestros. Tales estímulos los ordena el Ministerio con sus recursos, o el Departamento con los suyos. Tampoco puede la Junta arbitrar gastos para el mantenimiento y dotación física de los locales escolares porque eso parece corresponder al Departamento o al Municipio. Y sólo haciendo arriesgadas ficciones contables puede la misma Junta comprar y distribuir el material educativo que juzgue conveniente poner a disposición del magisterio. Queda así difícil entender qué implica en propiedad aquella función de las Juntas Administrativas de los

\footnotetext{
${ }^{80}$ Decreto 102 de 1976, art. 4, i).

Digitalizado por RED ACADEMICA
} 
FER, recién transcrita, que les ordena: "definir, organizar y administrar los servicios educativos...

El divorcio entre recursos y competencias es, pues, no sólo real sino multifacético. Dicho divorcio no surgió caprichosamente sino como resultado de soluciones de compromiso a otros problemas. Pero es manifiesto que con tal divorcio se perjudica de manera significativa el logro de más y mejor educación pública.

\section{Otros desarreglos administrativos}

Entre los varios otros problemas administrativos y financieros detectados por la investigación aquí presentada, cabe destacar cuatro: primero, para los fines de diseño presupuestal el Ministerio de Educación dispone de un sistema de información muy deficiente; segundo, en términos de la composición del presupuesto de gastos del mismo Ministerio, aquella tiende a desconocer rubros fundamentales; tercero, la estructura organizacional del sector educativo no permite un manejo expedito de los conflictos laborales del magisterio; y cuarto, la conformación de las Juntas Administradoras de los FER las hace poco efectivas. Conviene comentar sumariamente cada punto.

Como derivado parcial de la ambigüedad de competencias atrás relatada y del traspaso progresivo y un tanto forzado de la carga financiera, relativa a la enseñanza primaria, de los Departamentos a la Nación, el Ministerio de Educación se ha visto constreñido a preparar presupuestos de gastos para el sector de la enseñanza primaria sin la adecuada información. Prueba palpable de ello son los notables desajustes observados entre el cálculo inicial del costo del Estatuto Docente hoy vigente dado a conocer cuando lo suscribió el Presidente en 1979 y su costo real, o entre las transferencias proyectadas por el Ministerio de Educación para la vigencia de 1981, y el costo calculado de las mismas antes de concluir el año fiscal. Semejantes diferencias se explican en parte porque el Ministerio carece de archivo alguno donde conste, por ejemplo, cuánto gana cada maestro, cuántos años de servicio y cuál es su categoría en el escalafón. Esta información sólo está a disposición en algunos FER y principalmente en las Secretarías Departamentales de Educación, cuyos archivos no suelen ser ejemplo de orden y sistematización. De ahí que el Ministerio no tenga manera confiable de predecir, por ejemplo, cuántos maestros van a completar en un año dado los requisitos para ascender en el escalafón, ni menos cuántos de cuál escalafón al siguiente. Por consiguiente no puede hacer cálculos, siquiera bastante aproximados, del costo real de su nómina, y ni hablar sobre los estimativos del valor de las prestaciones sociales del magisterio para efecto de la reserva presupuestal del caso.

El segundo problema que se quiere aquí subrayar es uno que atañe los criterios para la distribución del presupuesto educativo de gastos. Porque dichos criterios obedecen a un contexto administrativo poco funcional. En concreto, la composición del gasto educativo que contempla el Ministerio de Educación, si bien reconoce diversos rubros, se centra en dos áreas: el pago del personal docente, y los gastos de inversión —considerando como tales casi exclusivamente la construcción de aulas, y en veces de vivienda para maestros, junto con la dotación mínima de pupitres y asientos. Se reflejan así los criterios propios de una entidad que no se siente directamente responsable de atender las necesidades reales de la educación primaria. Son más bien los criterios de la entidad que subsidia financieramente, como generalmente lo ha sido el Ministerio de Educación, en tanto que otro administra. El problema es que muchos gastos corrientes y fijos en que puede incurrir una escuela aparecen dentro del presupuesto oficial, cuando allí figuran, como programas adicionales, cuyo financiamiento parece depende más de la política imperante en un 
momento dado y/o de los recursos disponibles, que de las mismas necesidades de la escuela. Tal es el caso, por ejemplo, de la capacitación docente, cuyos recursos se arbitran dentro del presupuesto de inversión y sin criterios permanentes que garanticen su continuidad como programa. Igual cosa sucede con otros rubros como los de materiales de uso colectivo en el aula, textos y libros reglamentarios para el docente, adquisición de ayudas educativas, bibliotecas, implementos para el aseo de la escuela, mantenimiento de áreas deportivas, etc.

Tercero, también como efecto de las ambigüedades atrás anotadas y del divorcio entre competencias y recursos, el sector educativo carece de una estructura organizacional apta para manejar los reclamos salariales, y en general laborales, del magisterio. El maestro no sabe a ciencia cierta ante quién presentar tales reclamos porque no es claro quién sea su patrono. El que lo nombró? El que le ordena trasladarse de un lado a otro? El que supervisa? EI FER que le paga? EI Ministerio? En realidad, según el problema que le preocupa al maestro deberá presentar su queja en un nivel gubernamental o en otro, a una entidad o a otra. Pero hay tópicos donde ningún nivel o agencia se declara competente, como en el caso del pago de algunas prestaciones sociales ya causadas. Se sigue entonces que parte del origen de las huelgas del magisterio, y de su prolongada duración en ocasiones, nace de esta confusa situación administrativa. Que por cierto conduce a un fenómeno organizacional asimismo indeseable, a saber, todo problema laboral colectivo tiende a desplazarse al despacho mismo del Ministro porque no existe otra instancia previa que lo pueda resolver.

Cuarto, tal como atrás se ilustró, la administración directa de la educación primaria ha sido confiada ante todo a las Juntas Administradoras de los FER, al menos en la medida en que las autoridades departamentales así lo han permitido. Dejando de lado el problema de la duplicidad de funciones entre dichas Juntas y las Secretarías Departamentales de Educación, cabe aquí subrayar algunas serias deficiencias que provienen de la composición y funciones de tales Juntas. Recuérdese primero su composición: desde 1976 conforman dichas Juntas siete personas: el Gobernador del Departamento, quien la preside; los Secretarios Departamentales de Educación y de Hacienda o en reemplazo de este último, el Jefe Departamental de Planeación; el Delegado del Ministerio ante el FER; el gerente regional del ICCE; el director regional del ICETEX; y un representante del magisterio ${ }^{81}$. Ahora bien, obsérvese que, aun cuando el peso del Gobernador sobresale en la Junta - ya que puede contar con tres votos seguros a su favor en la mayoría de los casos, a saber, el suyo y el de sus dos secretarios-, no obstante, el hecho es que las autoridades departamentales no controlan la Junta. Más aún, ésta puede tomar decisiones por mayoría contrarias a las preferencias de aquellos. Todavía más, dado que según las normas vigentes, "los Gobernadores, Intendentes, Comisarios y el Alcalde del Distrito Especial de Bogotá serán los ejecutores de las decisiones de las Juntas Administradoras de los FER", el jefe de la entidad territorial corre el riesgo de quedar obligado a ejecutar decisiones a las cuales pudo haberse opuesto, y/o que quizás fueron aprobadas con el voto positivo o la abstención de sus propios subalternos, los Secretarios de Educación y Hacienda ${ }^{82}$.

Tal vez la disfuncionalidad más importante que aquí conviene destacar se relaciona con el hecho de confiar la administración directa de unos servicios como los educativos a una Junta, en lugar de a una persona. Una Junta sólo excepcionalmente podrá ser una buena administradora. $Y$ menos una Junta como la del FER, cuyos miembros desempeñan

\footnotetext{
${ }^{81}$ Decreto 102 de 1976 , art. 3.

${ }^{82}$ Decreto 102 de 1976 , art. 6.
} 
ocupaciones de tiempo completo en otra parte y apenas marginalmente pueden atender los requerimientos de aquella. Esta situación ha conducido a que, o las Juntas descuiden sus funciones, o ideen mecanismos originales, de valor incierto, para atenderlas. Tal es el caso del Departamento del Magdalena donde la Junta Administradora del FER creó un Comité de Administración Educativa con el encargo de regir la educación primaria ${ }^{83}$. Tal Comité está compuesto por seis personas, el Secretario de Educación y tres funcionarios suyos, y el Delegado del Ministerio ante el FER, con un funcionario suyo. Todavía no se tienen elementos de juicio para evaluar un tal mecanismo, pero preocupa ver cómo las nuevas entidades administradoras de la educación primaria, o sea las Juntas Administradoras de los FER, tienen que inventar medios de delegar en otros lo que a ellas corresponde en propiedad pero no pueden cumplir.

\section{Sugerencias}

Los problemas administrativos y presupuéstales de la educación primaria oficial atrás planteados, unidos a las experiencias adquiridas cuando se los investigó, permiten proponer, o una serie de recomendaciones específicas de tipo remedial, o unos planteamientos de fondo con sugerencias de orden general. Aquí hemos optado por lo segundo.

Urge una clara definición oficial —-tomada por el Congreso Nacional a iniciativa del Ejecutivo- sobre la distribución de competencias a propósito de la educación primaria entre los diversos niveles y entidades del gobierno. En realidad, aunque en esto cabe confiar unas funciones a un nivel de gobierno y otras a otro - por ejemplo, la construcción y dotación inicial de las escuelas puede atribuirse a uno, su mantenimiento físico y dotación posterior a otro-, la función docente —es decir, el suministro de maestros, su pago, su distribución y capacitación- deberían ser la responsabilidad directa de un sólo nivel de gobierno, al cual hay que dotar de los recursos del caso, sea mediante recursos propios, sea mediante transferencias obligatorias, y por tanto predecibles —al estilo del situado fiscal. Cuál debe ser ese nivel, implica una decisión política de enorme trascendencia y debería ser objeto de un amplio debate nacional.

En concreto y como contribución a tal debate, nos atrevemos a proponer lo siguiente. La función docente debería quedar en manos de entidades territoriales regionales: Los Departamentos, Comisarías, Intendencias, Distrito Especial de Bogotá y las áreas metropolitanas, en el régimen administrativo actual, o en las manos de quienes reemplacen a éstas. Creemos que una tal descentralización refuerza y defiende nuestra democracia, permite un servicio más eficiente y efectivo, y corresponde mejor a la tradición político-administrativa del país.

Pero como la descentralización propuesta tiene sus dificultades, en particular las que se originan en la deficiente capacidad administrativa de algunos territorios, queremos apuntar a una fórmula intermedia. Por qué no pensar en una "descentralización diferencial", o sea, una descentralización que no es la misma para todas partes, que tiene por así decir grados o intensidad diversa. En concreto, la descentralización puede ser "máxima" o intensa en el caso de aquellos territorios - por ejemplo, Antioquia, Valle y el Distrito-donde el aparato administrativo regional llena ciertos requisitos, por concretar mediante Ley, de organización y seriedad administrativa. En otros casos cabría una

\footnotetext{
${ }^{83}$ Ver los Acuerdos 55 de 1979 y 32 de 1980 de la Junta Administradora del FER del Magdalena (Inéditos).
} 
descentralización "intermedia", y en unos cuantos — sería de esperar que fuesen muy pocos - una descentralización "mínima"

La descentralización diferencial permitiría evitar los elevados costos tanto de una centralización total, como de una descentralización indiscriminada que ya demostró sus múltiples vicios. Por otro lado, la descentralización diferencial haría posible un cambio de régimen administrativo según las circunstancias, porque se la puede hacer también "condicional". Es decir, el territorio que, dotado de un régimen de "máxima" descentralización administrativa, deja de cumplir unos requisitos mínimos podría retroceder a una régimen de descentralización "intermedia". Así como el Departamento o el área metropolitana, inicialmente clasificado como apto sólo para una descentralización "intermedia" puede, con el correr del tiempo, demostrar que ha logrado reunir los requisitos para el "máximo" grado de descentralización y ser promovido a ella. La descentralización diferencial y condicional es una fórmula que nos parece digna de un cuidadoso escrutinio.

\footnotetext{
${ }^{84}$ El informe Bird-Wiesner propone unas fórmulas concretas de descentralización fiscal que corresponden de lleno al enfoque "diferencial" aquí propuesto. Por supuesto, se pueden idear, otras fórmulas de descentralización diferencial.
} 